\title{
Evaluation of Decomposition Property of Photoresist by Oxygen Radicals Using Helium-Oxygen Mixtures
}

\author{
Masashi Yamamoto ${ }^{1^{*}}$, Koki Akita ${ }^{1}$, Shiro Nagaoka ${ }^{2}$, \\ Hironobu Umemoto ${ }^{3,4}$, and Hideo Horibe ${ }^{4}$ \\ ${ }^{1}$ Department of Electrical and Computer Engineering, National Institute of Technology, \\ Kagawa College, 355 Chokushi-cho, Takamatsu, Kagawa 761-8058, Japan \\ ${ }^{2}$ Department of Electronic Systems Engineering, National Institute of Technology, \\ Kagawa College, 551 Kohda, Takuma-cho, Mitoyo, Kagawa 769-1192, Japan \\ ${ }^{3}$ Shizuoka University, Johoku, Naka, Hamamatsu, Shizuoka 432-8561, Japan \\ ${ }^{4}$ Department of Applied Chemistry and Bioengineering, Graduate School of Engineering, \\ Osaka City University, 3-3-138, Sugimoto-cho, Sumiyoshi, Osaka 558-8585, Japan \\ *m-yamamoto@t.kagawa-nct.ac.jp
}

\begin{abstract}
We have previously demonstrated that photoresist removal rate is enhanced by adding a trace amount of $\mathrm{O}_{2}$ to the atmosphere in which $\mathrm{H}$ radicals are produced from $\mathrm{H}_{2}$ on a hot metal filament. In this case, not only $\mathrm{H}$ radicals but also $\mathrm{O}$ and $\mathrm{OH}$ radicals are produced. The populations of $\mathrm{O}$ and $\mathrm{OH}$ radicals are a few hundredth parts of that of $\mathrm{H}$ radicals, but these radicals must play important roles. It is not clear which radicals contribute more to the enhancement of the removal rate. We used $\mathrm{He} / \mathrm{O}_{2}$ mixtures in this study, instead of $\mathrm{H}_{2} / \mathrm{O}_{2}$, to produce $\mathrm{O}$ radicals without co-producing $\mathrm{H}$ and $\mathrm{OH}$ to make clear the contribution of $\mathrm{O}$ radicals on the removal rate. The removal rate increased slightly with increasing the $\mathrm{O}_{2}$ additive amount when the filament was unheated. This may be caused by thermal oxidation. On the other hand, the removal rate with a hot filament decreased by the addition of $\mathrm{O}_{2}$. In short, the removal rate is not enhanced by $\mathrm{O}$ radicals. The enhancement in $\mathrm{H}_{2} / \mathrm{O}_{2}$ mixtures must only be ascribed to $\mathrm{OH}$ radicals.
\end{abstract}

Keywords: Photoresist, Removal, Hardening, Crosslinking, O Radical, $\mathrm{He} / \mathrm{O}_{2}$ mixture

\section{Introduction}

Photoresists are widely used to fabricate fine patterns on the substrate in the manufacturing process for nano- and micro-devices. The role of photoresist is to protect the predetermined area from some processes, e.g. deposition, etching and ion implantation. Photoresists must be removed for the next step, except in some photoresists such as SU-8, which is used for MEMS process. Chemicals, which are hazardous to humans and the environment, are widely used to remove photoresists [1,2]. An enormous amount of chemicals is used to shorten the process times in batch processes. There are several problems in this technique, such as environmental impacts and costs of chemicals in photoresist removal.

To overcome the above issues, we have examined a way of photoresist removal using $\mathrm{H}$ radicals $[3,4]$.
$\mathrm{H}$ radicals can be produced efficiently by decomposing molecular $\mathrm{H}_{2}$ on metal hot catalysts [5-7]. The removal rate comparable to oxygen plasma has been accomplished by optimizing the removal conditions with $\mathrm{H}$ radicals [3]. On the other hand, as far as only $\mathrm{H}$ radicals are used, the removal rate is reaching a limit. To further enhance, we focused on $\mathrm{OH}$ radicals, whose reactivity against unsaturated hydrocarbons is high $[8,9]$.

To produce $\mathrm{OH}$ radicals, we examined a way of adding a trace amount of $\mathrm{O}_{2}$ to the atmosphere in which $\mathrm{H}$ radicals are produced from $\mathrm{H}_{2}$ on metal hot filament surfaces. The removal rate was found to be a few times higher than that in pure $\mathrm{H}_{2}$ systems [1014]. Not only $\mathrm{OH}$ radicals but also $\mathrm{O}$ radicals can be produced in such $\mathrm{H}_{2} / \mathrm{O}_{2}$ mixed systems $[5,15]$. According to Umemoto et al., the density of $\mathrm{O}$ and $\mathrm{OH}$ radicals generated on an Ir filament in the 
absence of photoresists is $4.2 \times 10^{11}$ and $1.6 \times 10^{10}$ $\mathrm{cm}^{-3}$, respectively, when the filament temperature is $2100 \mathrm{~K}$ and $\mathrm{O}_{2}$ gas pressure is $1.0 \mathrm{~Pa}$ [15]. The population of $\mathrm{OH}$ radicals is less than a tenth part of that of $\mathrm{O}$ radicals. It is not clear which radicals contribute more to the enhancement of the removal rate.

Our earlier study demonstrated that the enhancement has been observed when the gas flow rate of $\mathrm{O}_{2}$ against that of $\mathrm{H}_{2}$ is less than $10 \%$ [1014]. This saturation has been ascribed to the decrease in the $\mathrm{H}$ radical density. To avoid the complicated interactions between radicals, we used $\mathrm{He}$, instead of $\mathrm{H}_{2}$, in this study. Since ionization or electronic excitation is not expected on hot filament surfaces, only ground-state $\mathrm{O}$ radicals are expected for active species in $\mathrm{He} / \mathrm{O}_{2}$ mixed systems. The density of $\mathrm{O}$ radicals in the presence of $0.8 \mathrm{~Pa}$ of pure $\mathrm{O}_{2}$ has been measured to be as large as $2 \times 10^{12}$ $\mathrm{cm}^{-3}$ when the Ir filament temperature is $2350 \mathrm{~K}$ [16].

\section{Experimental}

The experiment apparatus and the procedure were similar to those described elsewhere [10-14]. The He gas ( $\geq 99.99 \%$; Takamatsu Teisan Co.) flow rate was fixed at $100 \mathrm{sccm}$ using a mass flow controller. (PE-D20; HORIBA STEC). The $\mathrm{O}_{2}$ gas $(\geq 99.5 \%$; Iwatani Sangyo Co. Ltd.) flow rate was varied between 0 and $10.0 \mathrm{sccm}$ using another mass flow controller (SEC-400MK3; STEC Inc.): i.e., the amount of added oxygen (flow rate ratio of $\mathrm{O}_{2}$ to $\mathrm{He}$ ) was varied between 0 and $10.0 \%$. The typical total pressure under processing was $2.7 \mathrm{kPa}$, as measured using a vacuum gauge (Baratron 622A12TAE; MKS Instruments Inc.).

As a hot filament catalyst, a resistively heated iridium filament $(99.9 \%, 0.5 \mathrm{~mm}$ diameter, $500 \mathrm{~mm}$ long; Tanaka Precious Metals) was used: it was coiled with 11 turns, with respective coil length and diameter of $40 \mathrm{~mm}$ and $8 \mathrm{~mm}$. The distance between the catalyst and the substrate was $20 \mathrm{~mm}$. A DC power supply (EX-750L2; Takasago Ltd.) was used to heat the catalyst. The catalyst temperature at the central position, which was measured through a quartz window using a two-wavelength ( 0.80 and $1.05 \mu \mathrm{m})$ infrared radiation thermometer, was 1800 $\pm 10{ }^{\circ} \mathrm{C}$. The input power was $230 \mathrm{~W}$ in pure $\mathrm{H}_{2}$ system. The power in $\mathrm{He} / \mathrm{O}_{2}$ mixed systems was adjusted from $145 \mathrm{~W}$ to $165 \mathrm{~W}$; it increased with increasing the amount of added $\mathrm{O}_{2}$.

A positive-tone novolak photoresist (Tokyo Ohka Kogyo OFPR-800) was used in this study. It was spin-coated onto a $\mathrm{Si}$ wafer using a spin coater (Kyowariken K-359 S-1) at $2.6 \times 10^{3} \mathrm{rpm}$ for $20 \mathrm{~s}$ and was prebaked in an oven (Koyo Thermo Systems CLO-2AH) at $100{ }^{\circ} \mathrm{C}$ for $60 \mathrm{~s}$. The initial photoresist film thickness was $1.2 \mu \mathrm{m}$, which was measured using a surface texture measuring instrument (Tokyo Seimitsu Surfcom 480A).

Changes in film thickness were evaluated using thin film interference of the photoresist [10]. By thin film interference, the peaks and valleys of the reflected light intensity were observed alternately during changes in film thickness. The film thickness can be calculated from the reflected light intensity. Green laser light from the optical source $(520 \mathrm{~nm}$, $150 \mathrm{~mW}$; CivilLaser, Naku Technology Co. Ltd.) entered the center of the stage at an incident angle against the substrate surface of $76^{\circ}$. A Si photodiode (S1787-04; Hamamatsu Photonics K.K.) in reverse bias was used as a photodetector to measure the intensity of light reflected from the substrate. Its cathode was connected to $+5 \mathrm{~V}$ DC through a $60 \mathrm{k} \Omega$ resistor. The reflected light intensity was ascertained by correcting the voltage between both ends of the resistor.

We heated the substrate using a substrate stage heater to evaluate the dependence of the removal rate on the substrate surface temperature. A sheath thermocouple (TK $\varphi 1.6 \times \mathrm{L} 300$; As One) was used for the surface temperature measurement. The thermocouple was placed on the substrate surface $20 \mathrm{~mm}$ distant from the stage center. The temperature and film thickness were measured simultaneously at $0.2 \mathrm{~s}$ intervals. The removal rate was calculated from the average decrease in film thickness during $2 \mathrm{~s}$.

\section{Results and discussion}

Figure 1 shows the removal rate of novolak photoresist as a function of the substrate surface temperature in $\mathrm{H}_{2}$ or $\mathrm{He}$ atmosphere. Strictly speaking, the vertical axis of Fig. 1 is the decrease rate in film thickness, which includes the rates of not only removal by decomposition but also thermal shrinkage. However, just for simplicity, we would like to call removal rate. When the Ir filament was unheated, we can determine the removal (shrinkage) rate of photoresist. Pyrolysis must be minor below $350{ }^{\circ} \mathrm{C}$ because of the heat resistance of photoresist, which is mainly composed of a phenol resin [17]. When the filament was heated, the rate increased with increasing the temperature, although the rate in $\mathrm{He}$ is much smaller than that in $\mathrm{H}_{2}$. The increase in the removal rate when the filament is heated in the 
presence of $\mathrm{He}$ cannot be ascribed to metastable $\mathrm{He}$ atoms because its energy is too high to be excited on hot filament surfaces.

It should be remembered that some volatiles are effused from photoresist films, when the film is heated by stage heater and/or radiation from the hot filament. One of the major volatiles must be propyleneglycol monomethyl ether acetate (PGMEA), which is commonly used for the solvent of photoresist, remaining in the film. These volatiles can be decomposed on hot filament surfaces to produce radical species, including $\mathrm{H}$ radicals, which may decompose polymer films.

In order to evaluate the effect of oxygen addition on removal of photoresist in $\mathrm{He} / \mathrm{O}_{2}$ mixtures, we analyzed the removal property using peak separation. Figure 2 shows the results in $\mathrm{He}$ and $\mathrm{He} / \mathrm{O}_{2}$ mixtures and peak-fitting analysis. Here, as is the case for Fig. 1, removal is used to present both decomposition and shrinkage. The filament was not heated in these cases. It is found that the removal curve is separated into 5 peaks. Magnitude of peaks 1 and 3 increased with increasing the oxygen additive amount. On the other hand, magnitude of peaks 2, 4, and 5 stayed unchanged against the oxygen addition. The increase in the magnitude of peaks 1 and 3 might be ascribed to thermo-oxidative degradation by $\mathrm{O}_{2}$. These peaks are independent of each other, as described below.

Figure 3 shows removal rate of novolak photoresist as a function of the substrate surface temperature in $\mathrm{He} / \mathrm{O}_{2}$ mixtures when the filament was heated. To our surprise, the removal rate decreased significantly when oxygen was added. The cause of this decrease is probably the thermal

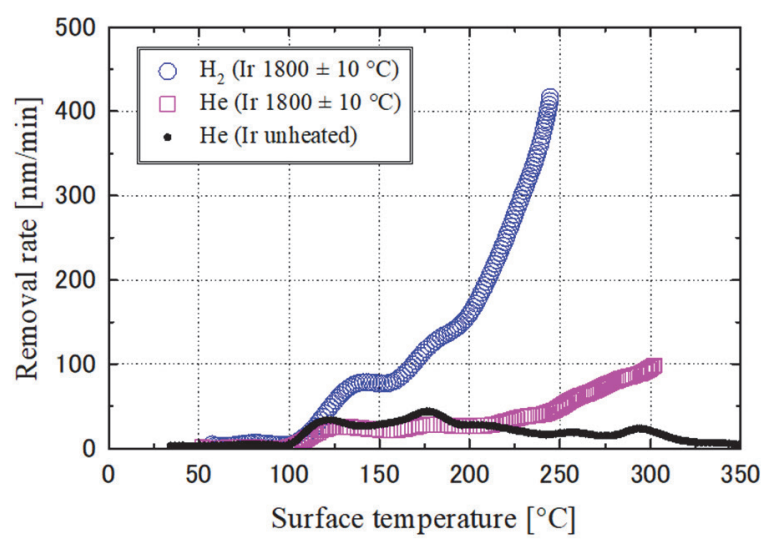

Fig. 1. Removal rate of novolak photoresist as a function of the substrate surface temperature in $\mathrm{H}_{2}$ or $\mathrm{He}$ atmosphere.

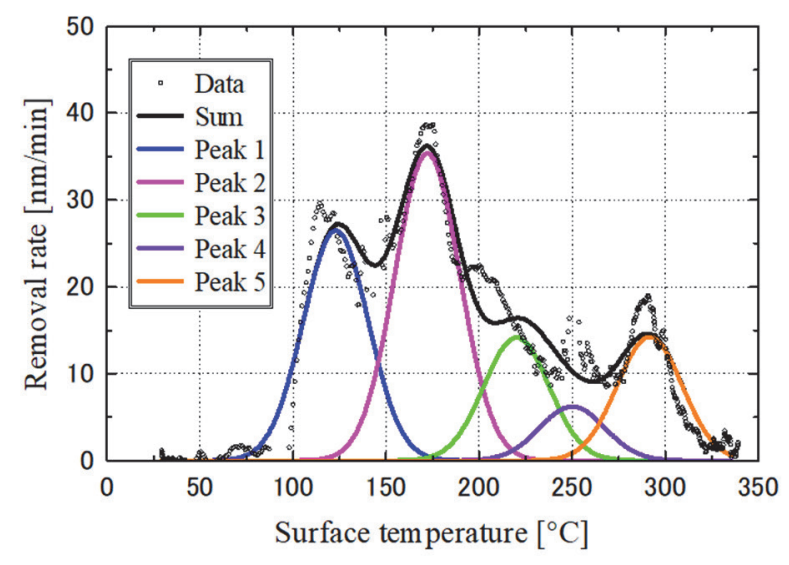

(a) $100 \mathrm{sccm} \mathrm{He}$

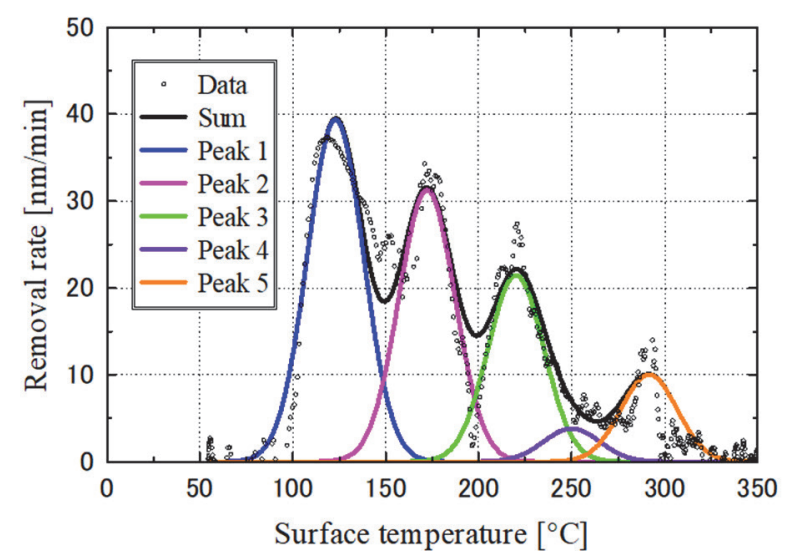

(b) $100 \mathrm{sccm} \mathrm{He}, 10.0 \mathrm{sccm} \mathrm{O}$

Fig. 2. The removal of novolak photoresist in $\mathrm{He} / \mathrm{O}_{2}$ mixtures and peak-fitting analysis. The filament is unheated. The center of peak 1 is $123^{\circ} \mathrm{C}$; peak 2 is 172 ${ }^{\circ} \mathrm{C}$; peak 3 is $220{ }^{\circ} \mathrm{C}$; peak 4 is $250{ }^{\circ} \mathrm{C}$; peak 5 is $292^{\circ} \mathrm{C}$. The sum from peak 1 to peak 5 is also illustrated.

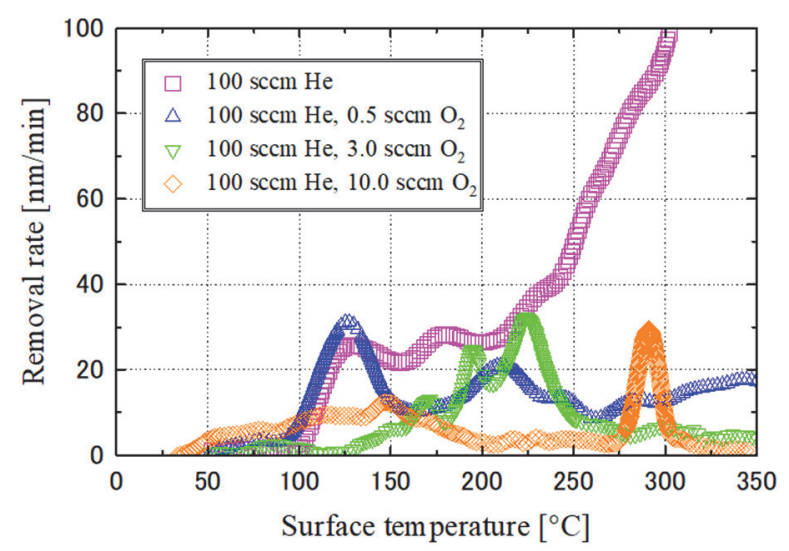

Fig. 3. Removal rate of novolak photoresist as a function of the substrate surface temperature in $\mathrm{He} / \mathrm{O}_{2}$ mixtures. The filament is heated to $1800 \pm 10^{\circ} \mathrm{C}$. 
hardening and crosslinking. Our earlier study suggests that the photoresist is hardened thermally and its removal rate decreases with increasing the baking temperature in the air [18]. Some hardening layers might be produced on the film surfaces. The layers can prevent not only the removal of photoresist but also volatilization of the solvent. The peak at the temperature of $100-150{ }^{\circ} \mathrm{C}$ should represent the shrinkage by volatilization of the solvent. When the photoresist with surfacehardened layer is heated, the layer explodes by increasing the internal pressure induced by escaped gas from the lower layer [19]. This phenomenon is named as "popping", which is famous problem in the removal of ion-implanted photoresist. We confirmed an alligatoring on the surface of retrieved samples from the chamber in such hydrogen-free systems, and it looked like popping. In addition, radical species produced from effused volatiles might be deactivated by added oxygen.

Umemoto et al. have measured the absolute Oradical densities not only in $\mathrm{H}_{2} / \mathrm{O}_{2}$ mixed systems but also in pure $\mathrm{O}_{2}$ systems when the $\mathrm{Ir}$ catalyst temperature was less than $2350 \mathrm{~K}[15,16]$. In both systems, the densities of O-radicals increase with increasing the filament temperature and the oxygen amount. The density in the present system is estimated to be about $10^{12} \mathrm{~cm}^{-3}$. In Fig. 3, the removal rate increased slightly at $100-200{ }^{\circ} \mathrm{C}$ when the $\mathrm{O}_{2}$ amount was $10.0 \mathrm{sccm}$. This slight increase may be ascribed to decomposition by $\mathrm{O}$ radicals. In any case, however, the photoresist must be decomposed little by $\mathrm{O}$ radicals.

When the filament was not heated, five peaks could be identified, as is shown in Fig. 2. On the other hand, when the filament was heated with an $\mathrm{O}_{2}$ flow, particular peaks are remarkable. When the oxygen additive amount is $0.5 \mathrm{sccm}$, peaks 1 and 3 are observed. The removal rate at the temperature range of peak 1 is as large as that of pure He, while the rate depends little on the substrate temperature over $170{ }^{\circ} \mathrm{C}$. In the case of $3.0 \mathrm{sccm}$, peak 1 becomes absent and peak 3 stands out. In the case of $10.0 \mathrm{sccm}$, peak 3 is absent but peak 5 is more remarkable. Additionally, the rate increased slightly at temperature range of $100-200{ }^{\circ} \mathrm{C}$. The decomposition reaction at lower temperatures might play no role in reaction at higher temperatures; e.g. only peak 5 is observed despite the absence of peaks 1 and 3 when the oxygen additive amount is 10.0 sccm. Therefore, the removal mechanisms corresponding to these peaks are independent of each other.

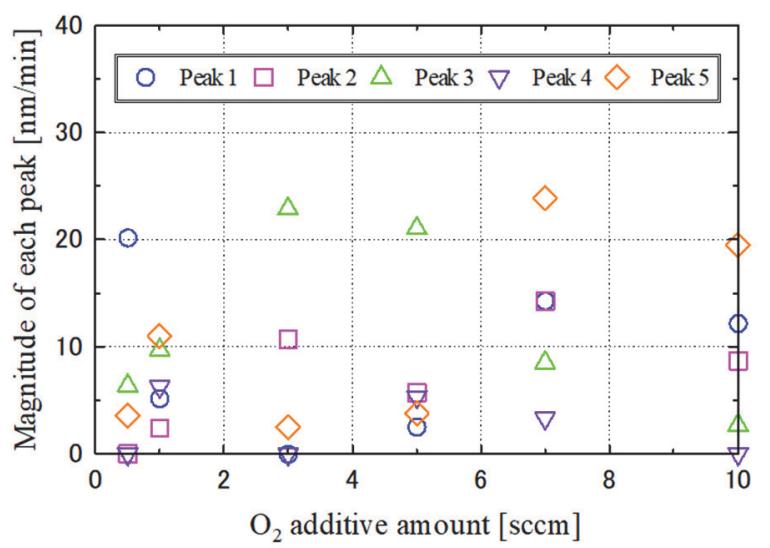

Fig. 4. Magnitude of each peak as a function of the oxygen additive amount in $\mathrm{He} / \mathrm{O}_{2}$ mixtures.

Figure 4 shows the magnitude of each peak as a function of the oxygen additive amount in $\mathrm{He} / \mathrm{O}_{2}$ mixtures. The magnitude of peak 1 decreased at 0.5 $3.0 \mathrm{sccm}$, and then increased gradually. The magnitude of peak 2 increased at $0.5-3.0 \mathrm{sccm}$, and then remained almost constant around $10 \mathrm{~nm} / \mathrm{min}$. The magnitude of peak 3 increased at $0.5-3.0 \mathrm{sccm}$, and then decreased gradually. The peak 4 remained almost constant and was a few $\mathrm{nm} / \mathrm{min}$. The magnitude of peak 5 is almost flat at $0.5-5.0 \mathrm{sccm}$, and then increased rapidly. The peaks shown in Fig. 2 were singly observed in Fig. 3. These independent behaviors suggest that the removal mechanisms of these peaks are different. Each peak would exist as a result of an independent hardening and/or crosslinking mode. The mode may be determined by a wide variety of factors, such as the substrate temperatures, including that caused by radiation heat, and the density of radicals.

\section{Conclusion}

Photoresist removal rate is enhanced by adding a trace amount of $\mathrm{O}_{2}$ to the atmosphere in which $\mathrm{H}$ radicals are produced from $\mathrm{H}_{2}$ on a hot metal filament. To investigate into the cause of this enhancement, we examined the relationship between $\mathrm{O}_{2}$ additive amount and the removal performance in $\mathrm{He} / \mathrm{O}_{2}$ mixed systems. The removal rate increased slightly with increasing the $\mathrm{O}_{2}$ additive amount when the filament was unheated. On the other hand, when the filament was heated, the removal rate decreased by the addition of $\mathrm{O}_{2}$. The enhancement of removal rate in the $\mathrm{H}_{2} / \mathrm{O}_{2}$ system cannot be attributed to the removal by $\mathrm{O}$ radicals, but should only be caused by $\mathrm{OH}$ radicals. 


\section{Acknowledgement}

This work was supported by JSPS KAKENHI Grant Number 19K04543.

\section{References}

1. H. Morinaga, T. Futatsuki, T. Ohmi, E. Fuchita, M. Oda, and C. Hayashi, J. Electrochem. Soc., 142 (1995) 966.

2. K. Hirose, H. Shimada, S. Shimomura, M. Onodera, and T. Ohmi, J. Electrochem. Soc., 141 (1994) 192.

3. M. Yamamoto, H. Horibe, H. Umemoto, K. Takao, E. Kusano, M. Kase, and S. Tagawa, Jpn. J. Appl. Phys., 48 (2009) 026503.

4. M. Yamamoto, H. Umemoto, K. Ohdaira, S. Nagaoka, T. Shikama, T. Nishiyama, and H. Horibe, J. Photopolym. Sci. Technol., 28 (2015) 303.

5. H. Umemoto and M. Moridera, J. Appl. Phys., 103 (2008) 034905.

6. T. W. Hickmott, J. Chem. Phys., 32 (1960) 810.

7. J. N. Smith, Jr. and W. L. Fite, J. Chem. Phys., 37 (1962) 898.

8. H. Sugimitsu, "Ozone no Kiso to Oyo (Basis and Application of Ozone)", Korin, Tokyo (1996) 20 (in Japanese).

9. S. Fujimura, K. Shinagawa, M. T. Suzuki, and M. Nakamura, J. Vac. Sci. Technol. B, 9 (1991) 357. 10. M. Yamamoto, H. Umemoto, K. Ohdaira, T.
Shikama, T. Nishiyama, and H. Horibe, Jpn. J. Appl. Phys., 55 (2016) 076503.

11. M. Yamamoto, K. Maejima, H. Umemoto, K. Ohdaira, T. Shikama, T. Nishiyama, and H. Horibe, J. Photopolym. Sci. Technol., 29 (2016) 639.

12. M. Yamamoto, T. Taki, T. Sunada, T. Shikama, S. Nagaoka, H. Umemoto, and H. Horibe, J. Photopolym. Sci. Technol., 31 (2018) 419.

13. M. Yamamoto, T. Shiroi, T. Shikama, S. Nagaoka, H. Umemoto, and H. Horibe, $J$. Photopolym. Sci. Technol., 32 (2019) 609.

14. M. Yamamoto, S. Nagaoka, H. Umemoto, K. Ohdaira, T. Nishiyama, and H. Horibe, Int. J. Polym. Sci., 2017 (2017) 2983042.

15. H. Umemoto, H. Kusanagi, K. Nishimura, and M. Ushijima, Thin Solid Films, 517 (2009) 3446.

16. H. Umemoto and H. Kusanagi, J. Phys. D: Appl. Phys., 41 (2008) 225505.

17. Ed. Osaka Municipal Technical Research Institute and Japan Society of Plastics Technology, "Plastic Dokuhon", Plastic Age, Tokyo, 1985, 14th ed (in Japanese).

18. T. Maruoka, Y. Goto, M. Yamamoto, H. Horibe, E. Kusano, K. Takao, and S. Tagawa, J. Photopolym. Sci. Technol., 22 (2009) 325.

19. T. Miura, M. Kekura, H. Horibe, and M. Yamamoto, J. Photopolym. Sci. Technol., 21 (2008) 311. 